\title{
Fosfito de potássio e ulvana no controle da mancha foliar da gala em macieira
}

\author{
Leonardo Araújo ${ }^{1}$, Marciel J. Stadnik ${ }^{1}$, Leandro C. Borsato ${ }^{1} \&$ Rosa M. Valdebenito-Sanhueza ${ }^{2}$ \\ ${ }^{1}$ Departamento de Fitotecnia, Centro de Ciências Agrárias, Universidade Federal de Santa Catarina, Cx. Postal 476, \\ 88040-900, Florianópolis, SC, Brasil; ${ }^{2}$ Embrapa, Estação Experimental de Frutas Temperadas, Cx. Postal 1513, 95200-000, \\ Vacaria, RS, Brasil
}

Autor para correspondência: Marciel J. Stadnik, e-mail: stadnik@cca.ufsc.br

\begin{abstract}
RESUMO
Este trabalho teve como objetivo estudar comparativamente a ação do fosfito de potássio e do polissacarídeo ulvana sobre Colletotrichum gloeosporioides "in vitro" e em plântulas de macieira (Malus domestica). Em meio BDA, avaliou-se o efeito de concentrações de fosfito de potássio $\left(0,0,0625,0,125,0,25\right.$ e $\left.0,5 \mu \mathrm{L} / \mathrm{mL} ; 40 \% \mathrm{P}_{2} \mathrm{O}_{5}-20 \% \mathrm{~K}_{2} \mathrm{O}\right)$ e ulvana $(0,1,5,10$ e $20 \mathrm{mg} / \mathrm{mL})$ sobre o crescimento micelial do fungo. Para verificar o efeito preventivo, em plântulas de macieira cultivadas em casa-de-vegetação, pulverizou-se fosfito $(3 \mu \mathrm{L} /$ $\mathrm{mL})$ ou ulvana $(10 \mathrm{mg} / \mathrm{mL})$ somente nas folhas inferiores e inoculou-se uma suspensão de $3 \times 10^{5}$ conídios $/ \mathrm{mL} 3$ e 6 dias após o tratamento. Aos 4, 6 e 8 dias após a inoculação, a porcentagem de área foliar necrosada foi avaliada em folhas inferiores e superiores e com estes dados calculou-se a AACPD. Na verificação do efeito curativo, aplicou-se fosfito ou ulvana 24 h após a inoculação. Em meio de cultura, o fosfito reduziu o crescimento micelial, enquanto a ulvana não afetou o fungo. $\mathrm{O}$ tratamento preventivo de ulvana reduziu a severidade local $\mathrm{e}$ sistemica em $65 \%$. Ao contrário da ulvana, o fosfito teve efeito curativo quando aplicado $24 \mathrm{~h}$ após a inoculação. Os resultados indicam que o fosfito de potássio tem ação direta sobre o fungo, enquanto a ulvana provavelmente induz resistência à mancha foliar da gala em macieira.
\end{abstract}

Palavras chave: Colletotrichum gloeosporioides, Malus domestica, Ulva fasciata, alga verde, controle de doença.

\section{ABSTRACT \\ Potassium phosphite and ulvan in the control of 'Gala' leaf spot on apple}

This work aimed to make a comparative study of the mode of action of potassium phosphite and the polysaccharide ulvan on Colletotrichum gloeosporioides "in vitro" and on apple seedlings. Different concentrations of potassium phosphite $(0,0.0625,0.125,0.25$ and $\left.0.50 \mu \mathrm{L} / \mathrm{mL} ; 40 \% \mathrm{P}_{2} \mathrm{O}_{5}-20 \% \mathrm{~K}_{2} \mathrm{O}\right)$ and ulvan $(0,1,5,10$ and $20 \mathrm{mg} / \mathrm{mL})$ were evaluated against fungus mycelium growth on PDAmedium. To verify the preventive effect, apple seedlings were grown in greenhouse, their lower leaves sprayed with phosphite $(3 \mu \mathrm{L} / \mathrm{mL})$ or ulvan $(10 \mathrm{mg} / \mathrm{mL})$ and inoculated with a suspension of $3 \times 10^{5}$ conidia $/ \mathrm{mL}, 3$ or 6 days after treatment. On the $4^{\text {th }}, 6^{\text {th }}$ and $8^{\text {th }}$ day after inoculation, the percentage of leaf area with necrosis was evaluated on lower as well as upper leaves and the AUDPC was calculated. To verify the curative effect, phosphite or ulvan was applied $24 \mathrm{~h}$ after inoculation. Phosphite reduced mycelial growth on culture medium, while ulvan did not affect it. The preventive treatment of ulvan reduced disease severity locally and systemically by $65 \%$. In contrast to ulvan, phosphite presented a curative effect when applied $24 \mathrm{~h}$ after inoculation. The results indicate that potassium phosphite has a direct effect on fungus, whereas ulvan probably induces resistance to 'Gala' leaf spot in apple plants.

Keywords: Colletotrichum gloeosporioides, Malus domestica, Ulva fasciata, green algae, disease control.

A maçã (Malus domestica Borkh.) é atualmente a segunda fruta mais importante de clima temperado no Brasil, sendo Santa Catarina o principal estado produtor com $55 \%$ da produção nacional. Entre os principais fatores que afetam a produtividade da macieira destacam-se o baixo número de horas de frio, alta precipitação na primavera e no verão, alta umidade relativa do ar e ocorrência de doenças (Epagri, 2002). Em 1983 constatou-se no Paraná uma nova doença da macieira que foi denominada de mancha foliar da gala em vista de ocorrer exclusivamente na cultivar Gala. Mais tarde, a doença foi encontrada em outras localidades e atualmente é presente em todas as regiões produtoras de maçã no sul do Brasil (Epagri, 2002). A mancha foliar da gala (MFG) é causada principalmente por Colletotrichum gloeosporioides (Penz.) Penz. \& Sacc. Outras espécies do gênero Colletotrichum como C. acutatum J.H. Simmonds podem também estar associadas à doença, mas são menos freqüentes. O patógeno possui uma grande variabilidade genética, o que dificulta os diferentes estudos e controle dessa doença (Hamada, 2005).

Os sintomas iniciais da doença são manchas de coloração vermelho a roxo, já visíveis dois dias após a infecção e que evoluem para manchas necróticas de formato irregular. As folhas lesionadas amarelecem e caem precocemente, entre oito a 10 dias após os primeiros sintomas em temperaturas acima de $20^{\circ} \mathrm{C}$ (Crusius et al., 
2002). A MFG manifesta-se principalmente no verão, quando pode provocar desfolhamento superior a $75 \%$ e, como conseqüência, reduzir a produção das plantas no ano seguinte (Epagri, 2002). Longos períodos de molhamento foliar, alta umidade relativa do ar e temperaturas elevadas são as principais condições favoráveis à infecção por Colletotrichum (Crusius et al., 2002; Hamada, 2005).

O controle da doença é feito principalmente com fungicidas que devem ser aplicados durante o ciclo todo nas cultivares suscetíveis (Crusius et al., 2002). Dentre os tratamentos químicos indicados, os fosfitos são atualmente recomendados. Os fosfitos são fertilizantes foliares que têm efeito antifúngico, porém, há dúvidas sobre o seu modo exato de ação. Alguns autores comprovaram a ação direta do fosfito sobre fungos (Guest \& Grant, 1991). Por outro lado, Saindrenant et al. (1988) atribuiu à síntese de fitoalexinas eliciada por fosfitos, como mecanismo de controle de Phytophthora cryptogea em feijão caupi. No Brasil, os fosfitos vêm sendo utilizados para controlar doenças de macieira, em especial a sarna causada por Venturia inaequalis (Boneti \& Katsurayama, 2005). Outros métodos alternativos a fungicidas para o controle da MFG são ainda pouco explorados.

Algas produzem diversos compostos bioativos, como aqueles que inibem o crescimento de microrganismos e/ou induzem a resistência da planta a patógenos (Stadnik \& Paulert, 2008). As paredes celulares das algas são constituídas por polissacarídeos complexos, os quais podem eliciar uma série de respostas de defesa da planta. Isso acontece porque, com a degradação desses polissacarídeos, há liberação de oligômeros que estão naturalmente envolvidos no reconhecimento celular das interações planta-patógeno (Klarzynski et al., 2000; Cluzet et al., 2004; Stadnik \& Maraschin, 2004). A laminarina (oligômero linear de $\beta-1,3$ glucana) obtida de uma alga marrom (Laminaria digitata) de ocorrência freqüente no hemisfério norte é, atualmente, o exemplo mais bem sucedido e vem sendo usada para controlar diferentes doenças de plantas (Klarzynski et al., 2000).

Ulva sp. (alface-do-mar) é uma macroalga verde comum no litoral brasileiro, que apresenta rápido crescimento e produz grande quantidade de biomassa, especialmente em ambientes eutrofizados. A ulvana (unidades repetidas de ácido ulvanobiurônico-3-sulfato) é um polissacarídeo solúvel dessa alga que pode induzir resistência em plantas de alfafa a Colletotrichum trifolii (Cluzet et al., 2004) e a $C$. lindemunthianum (Paulert, 2005). A indução de resistência em plantas é um fenômeno muito comum, que pode resultar de uma pré-infecção por patógeno ou tratamento com compostos de natureza química variada. Consiste em um método moderno, eficiente e uma alternativa menos agressiva à saúde humana e ao equilíbrio dos agroecossistemas (Stadnik \& Maraschin, 2004). O presente trabalho teve por objetivo estudar o efeito do fosfito de potássio e ulvana sobre C. gloeosporioides "in vitro" e em experimentos com tratamentos preventivos e pós-infeccional em plântulas de macieira 'Gala'.
Utilizou-se o fosfito de potássio $\left(40 \% \mathrm{P}_{2} \mathrm{O}_{5}\right.$ e $20 \%$ $\mathrm{K}_{2} \mathrm{O}$ ) de uma formulação comercial (Fitofos $\mathrm{K}$ plus ${ }^{\circledR}$, Suquimo, Espanha). A ulvana foi obtida de Ulva fasciata conforme descrito por Paulert et al. (2007). Para tanto, $100 \mathrm{~g}$ da alga seca foram autoclavados por $2 \mathrm{~h}$ a $110^{\circ} \mathrm{C} \mathrm{em} 1 \mathrm{~L}$ de água destilada. A solução aquosa foi filtrada e a precipitação do polissacarídeo foi feita pela adição de três volumes de etanol $\left(98^{\circ} \mathrm{GL}\right)$, seguido de resfriamento a $-20^{\circ} \mathrm{C}$ por $48 \mathrm{~h}$. Os compostos precipitados foram coletados, secos a $40-45^{\circ} \mathrm{C}$ por $48 \mathrm{~h}$ até peso constante e mantidos a $5^{\circ} \mathrm{C}$ até utilização nos ensaios.

Em todos os experimentos utilizou-se o isolado CGF1 de C. gloeosporioides da coleção da Embrapa Uva e Vinho, proveniente de plantas doentes da cultivar Gala. Para obtenção de inóculo foram usadas culturas desenvolvidas em BDA por 10 dias a $25^{\circ} \mathrm{C}$ e $12 \mathrm{~h}$ de fotoperíodo. As colônias formadas foram raspadas superficialmente com alça de Drigalsky e a concentração da suspensão de conídios foi ajustada com câmara de Neubauer, conforme especificado em cada experimento.

Nos ensaios "in vitro", foram incorporados fosfito de potássio e ulvana ao meio $\mathrm{BDA}$ a $45^{\circ} \mathrm{C}$, imediatamente antes de vertê-lo sobre as placas de Petri de $9 \mathrm{~cm}$ de diâmetro. Para o fosfito de potássio, testaram-se as concentrações de $0,0,0625,0,125,0,25$ e $0,5 \mu \mathrm{L} / \mathrm{mL}$, em pH 2,0 (acidez característica do produto), e pH 7,0 (ajustado com $\mathrm{NaOH} 5$ $\mathrm{N})$. Para ulvana ( $\mathrm{pH} 7,0$ ), usaram-se as concentrações 0,1 , 5,10 e $20 \mathrm{mg} / \mathrm{mL}$. Um disco de $8 \mathrm{~mm}$ de diâmetro contendo micélio de C. gloeosporioides foi transferido para o centro de cada placa e incubou-se a $25^{\circ} \mathrm{C}$ sob $12 \mathrm{~h}$ de fotoperíodo. Diâmetros das colônias em sentido perpendicular foram medidos aos 2, 4 e 6 dias após o inicio da incubação com um paquímetro. Com os dados do diâmetro médio das colônias obtido em cada avaliação, foi calculado o IVCM (Índice de Velocidade de Crescimento Micelial) expresso em $\mathrm{mm} / \mathrm{dia}$ (Abreu, 2005), utilizando-se a fórmula: $\operatorname{IVCM}=(\mathrm{D}-\mathrm{Da}) /$ $\mathrm{N}$; onde: D: Diâmetro médio atual; Da: Diâmetro médio anterior; N: número de dias após a transferência.

Experimentos em casa-de-vegetação foram conduzidos com plântulas, obtidas de sementes de frutos de maçã 'Gala', com base em metodologia adaptada de Brisset et al. (2000), Epagri (2002) e Ortega et al. (1998). Distribuiu-se equidistantemente 25 sementes entre camadas de algodão previamente umedecido, em caixa plástica do tipo "gerbox" (11 cm x $11 \mathrm{~cm} \mathrm{e} \mathrm{3,5} \mathrm{cm} \mathrm{de} \mathrm{altura).} \mathrm{Para} \mathrm{a}$ quebra da dormência, as sementes foram mantidas a $5^{\circ} \mathrm{C}$ por 50 dias. Sementes germinadas que apresentavam radículas de comprimento $\geq 5 \mathrm{~mm}$ foram transferidas para sementeiras de isopor (68 cm x $34 \mathrm{~cm}$ e $6 \mathrm{~cm}$ de altura), contendo como substrato solo argiloso esterilizado previamente com formalina 1\%. Após 30 dias, as plântulas foram repicadas para vasos plásticos de $1 \mathrm{~L}$ contendo o mesmo substrato das sementeiras, onde cresceram por mais 45 dias até apresentarem, em média, 15 folhas expandidas. Irrigou-se de acordo com as necessidades hídricas da planta. Adubouse com fosfato monoamônio (12-61-0), colocando-se 0,25 g 
em cada vaso aos 45 dias de idade. Para controle de oídio e pulgões pulverizou-se, a cada 7 dias, enxofre $80 \%(5 \mathrm{~g} / \mathrm{L})$ e inseticida organodiclorvos C.E. ( $5 \mathrm{ml} / \mathrm{L})$. Um dia antes do tratamento/inoculação, as folhas foram lavadas para retirar o resíduo de enxofre. Para separar as folhas inoculadas e/ ou tratadas daquelas que se desenvolveram posteriormente à inoculação e/ou tratamento, inseriu-se um anel plástico colorido na região do pecíolo foliar, logo acima da última folha expandida.

Para avaliar o efeito preventivo do fosfito de potássio e da ulvana no controle da MFG, realizaram-se dois experimentos independentes em condições de casade-vegetação. Para tanto, protegeram-se as quatro folhas superiores com um saco plástico e em seguida, pulverizou-se uma solução de fosfito de potássio ( $3 \mu \mathrm{L} / \mathrm{mL}$ - concentração recomendada pelo fabricante) ou ulvana $(10 \mathrm{mg} / \mathrm{mL}$; Paulert (2005) com uma pistola acoplada a um motocompressor de ar (Marca Schulz ${ }^{\mathbb{R}}, 20 \mathrm{~mL} / \mathrm{min}, 25 \mathrm{lbf} / \mathrm{pol}^{2}$ ) nas 10 folhas inferiores das plântulas até atingir o ponto de escorrimento. Uma hora após o tratamento, os sacos plásticos foram retirados e as plantas permaneceram em casa-de-vegetação até o momento da inoculação. $\mathrm{O}$ fosfito de potássio e a ulvana foram aplicados 3 ou 6 dias antes da inoculação (dai) de acordo com Paulert (2005). Plantas tratadas com água destilada serviram como testemunhas nos dois experimentos. As plantas foram inoculadas com uma suspensão de $3 \times 10^{5}$ conídios/ml do C. gloeosporioides e incubadas no escuro a $100 \%$ UR e $27^{\circ} \mathrm{C}$ por $24 \mathrm{~h}$. Avaliou-se a severidade de $\mathrm{MFG}$ baseando-se na estimativa visual da porcentagem de tecido necrosado de cada folha aos 4, 6 e 8 dias após a inoculação. Com estes dados, calculou-se área abaixo da curva do progresso da doença (AACPD) das quatro folhas superiores (efeito sistêmico) e das folhas inferiores diretamente tratadas (efeito local).

Para avaliar o efeito pós-infeccional da aplicação de fosfito de potássio e ulvana no controle da MFG, as plantas foram inoculadas com uma suspensão de $3 \times 10^{5}$ conídios/ $\mathrm{ml}$ e mantidas no escuro a $100 \%$ UR e $27^{\circ} \mathrm{C}$. Plantas foram pulverizadas com fosfito de potássio e ulvana $24 \mathrm{~h}$ após a inoculação e as testemunhas com água destilada. Avaliou-se a severidade de cada folha aos 4, 6 e 8 dias após a inoculação e calculou-se a AACPD, conforme descrito anteriormente.

Adotou-se o delineamento completamente casualizado, com cinco repetições, nos teste "in vitro", e 11 repetições, nos testes "in vivo". Na análise estatística dos testes "in vivo" foram considerados somente os segregantes suscetíveis (com sintomas da MFG), ou seja, de 4 a 7 repetições. Os resultados dos testes "in vitro" foram submetidos à análise de regressão e dos experimentos “in vivo" à análise de variância, seguido do teste de separação de médias Tukey $(\alpha \leq 0,05)$, com o software Statistica - Stat Soft ${ }^{\circledR}$, versão 6.0.

A estimativa do índice de velocidade de crescimento micelial teve o melhor ajuste pelo modelo de regressão quadrática, que apresentou os maiores coeficientes de determinação e a melhor distribuição dos resíduos. Pela análise de regressão, quanto maior a concentração de fosfito de potássio no meio, menor a velocidade de crescimento micelial de C. gloeosporioides (Figura 1). Na maior concentração testada $(0,5 \mu \mathrm{L} / \mathrm{mL})$, sem correção do $\mathrm{pH}$ do meio, houve inibição quase total do crescimento micelial do fungo, em relação às testemunhas, aos 6 dias. Em pH 7, nesta mesma concentração, a redução do crescimento micelial foi em torno de 50\% (Figura 1). A ulvana não afetou o crescimento. A ação do fosfito "in vitro" foi menor quando o $\mathrm{pH}$ da solução do produto foi corrigido, o que sugere que as características ácidas do fertilizante interferiram no desenvolvimento do fungo diretamente. Estes dados demonstram que o fosfito de potássio tem ação fungistática, pois o fungo não cessou completamente o seu crescimento em nenhum dos tratamentos. A atividade direta do ácido fosforoso e de seu sal (fosfito) tem sido constatada freqüentemente em experimentos com Fosetyl-Al (Boneti \& Katsurayama, 2005). Segundo Guest \& Grant (1991), este fungicida é degradado rapidamente nos tecidos da planta até formar o ácido fosforoso $\left(\mathrm{H}_{3} \mathrm{PO}_{3}\right)$. Curiosamente, o FosetylAl possui baixa atividade "in vitro", porém seu metabólito, o ácido fosforoso, inibe fortemente os Oomicetes. Esse ácido é muito fitotóxico, mas pode ser neutralizado por uma base, resultando em um sal denominado fosfito tal como $\mathrm{KH}_{2} \mathrm{PO}_{3}$ ou $\mathrm{K}_{2} \mathrm{HPO}_{3}$ Os fosfitos são menos fitotóxicos e apresentam alta atividade fungicida na planta (Boneti \& Katsurayama, 2005).

Nos ensaios "in vivo", as folhas superiores da macieira foram mais suscetíveis a $C$. gloeosporioides que as inferiores. Assim, enquanto nas quatro folhas superiores a AACPD foi em média 500, nas oito a 11 folhas inferiores a severidade média foi 230 (Figura 2). O fosfito de potássio quando

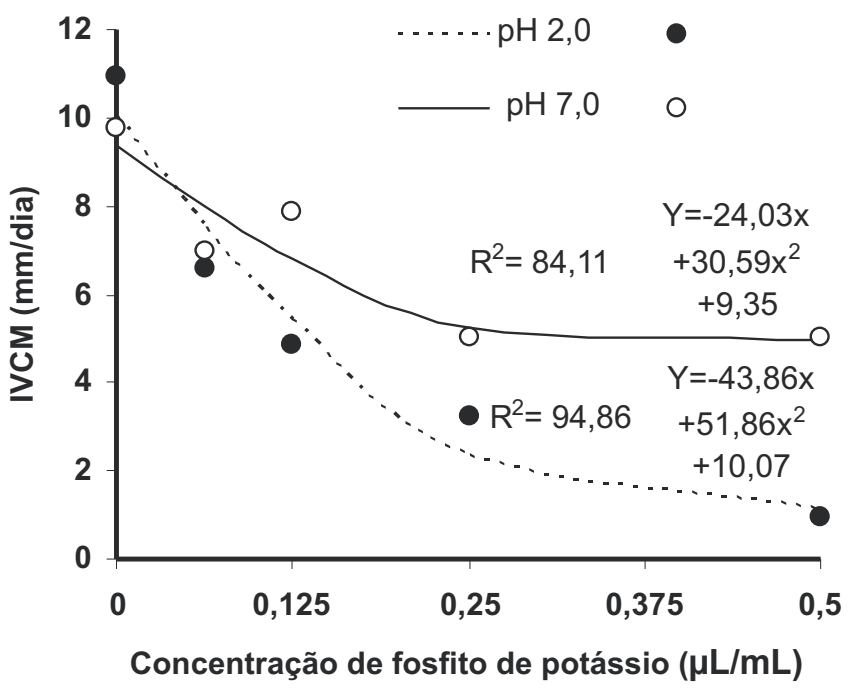

FIG. 1 - Efeito da concentração de fosfito de potássio em $\mathrm{pH}$ 2,0 e pH 7,0 sobre o índice de velocidade de crescimento micelial (IVCM) aos seis dias após a transferência de Colletotrichum gloeosporioides em meio de cultivo BDA. 
aplicado três e seis dias após a inoculação (d.a.i.) não afetou a severidade da doença, tanto em folhas tratadas diretamente quanto em folhas protegidas (efeito sistêmico). Boneti \& Katsurayama (2005) encontraram alta eficiência de controle da sarna (V. inaequalis) quando o fosfito de potássio $(3 \mathrm{ml} / \mathrm{L})$ foi pulverizado sete d.a.i., porém aplicações feitas a um, três e cinco dias tiveram baixa eficiência ou nenhum efeito sobre a doença. Estes resultados levam à conclusão que o fosfito de potássio poderia atuar indiretamente pela indução de resistência à sarna da macieira. Os fosfitos são translocados sistematicamente na planta via floema e xilema, e geralmente estão associados a fotoassimilados (Guest \& Grant, 1991; Saindrenant et al, 1988). São considerados uma forma não metabolizável de fósforo, rapidamente absorvida pelas folhas e que pode permanecer na planta por até 150 dias (Guest \& Grant, 1991). Assim, no presente trabalho, em que se aplicou o fosfito três ou seis d.a.i., a ineficiência do produto poderia ser explicada por uma das seguintes hipóteses: a) o intervalo de tempo entre a pulverização e indução foi insuficiente para aumentar a resistência das plantas; b) não houve indução de resistência a C. gloeosporioides ou, provavelmente, c) neste intervalo, o fosfito tenha sido translocado e acumulado nas partes mais ativas em crescimento como: gemas, folhas novas emitidas ou mesmo raízes, que são drenos conhecidos de fotoassimilados (Epagri, 2002). Entretanto, o fosfito de potássio aplicado uma única vez (24 h após a inoculação) teve efeito curativo, reduzindo os valores médios da AACPD em $90 \%$ nos tecidos previamente tratados. Ao contrário, a aplicação pós-infeccional de ulvana não afetou o desenvolvimento da MFG em experimentos realizados em casa-de-vegetação (Figura 3).

As folhas tratadas diretamente (efeito local) com solução de ulvana, bem como as folhas superiores protegidas com os sacos plásticos durante a pulverização (efeito sistêmico) 6 dai, exibiram uma redução da AACPD em torno de $65 \%$, em relação à testemunha (Figura 2). Em contraste, uma aplicação de ulvana aos três d.a.i. apresentou somente efeito local sobre a severidade da MFG. A caracterização molecular da ulvana foi realizada por Paulert et al. (2005), os quais demonstraram que este polissacarídeo não inibe diretamente o desenvolvimento de diferentes fungos e bactérias fitopatogênicas, mas induz resistência sistêmica à antracnose do feijoeiro. A ativação de vários genes de resistência a $C$. trifollii foi demonstrada também em alfafa tratada com polissacarídeos de Ulva sp. (Cluzet et al., 2004). No presente trabalho, somente o tratamento preventivo de ulvana realizado aos 6 dai resultou em redução sistêmica da severidade da $\mathrm{MFG}$, que poderia ser explicado pela necessidade de um intervalo de tempo para que a planta inicie a seqüência de eventos relacionados à ativação de sinais sistêmicos de defesa em partes da planta não tratadas. (Steiner \& Schönbeck, 1995; Cluzet et al., 2004). Por exemplo, acibenzolar-S-methyl reduz a severidade de $V$. inaequalis (Ortega et al., 1998) e de Erwinia amylovora (Brisset et al., 2000) em macieira e, a resistência induzida por esse composto, ocorre após o

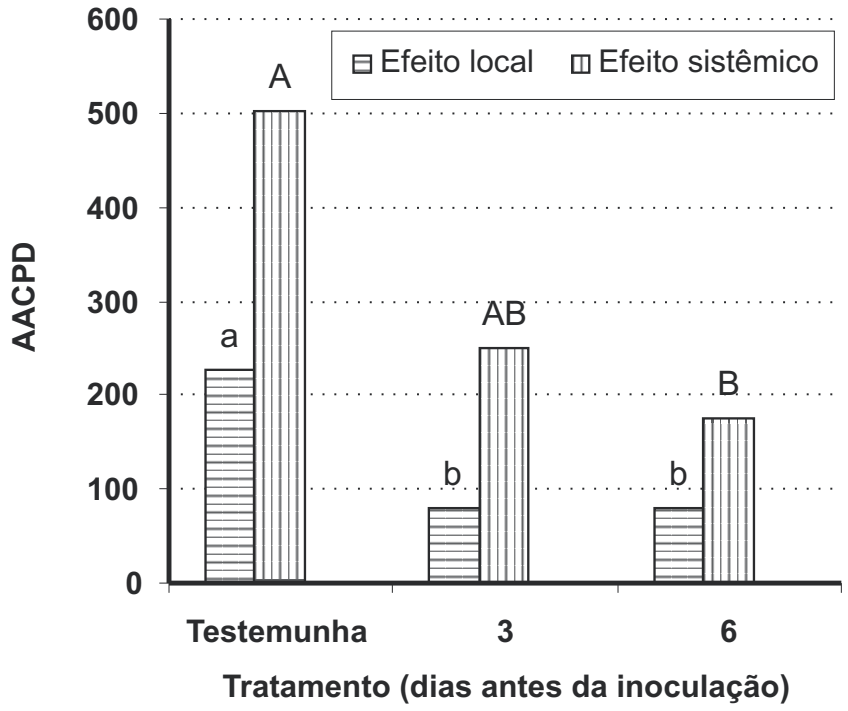

FIG. 2 - Efeito local e sistêmico de ulvana sobre a área abaixo da curva do progresso da doença (AACPD) em plântulas de macieira cv. Gala infectadas com Colletotrichum gloeosporioides. Para avaliação do efeito local, usou-se de 8 a 10 folhas inferiores e para o efeito sistêmico 4 folhas superiores. Colunas com mesmas letras minúsculas e maiúsculas indicam que não há diferença estatítica pelo teste de Tukey $\left(\alpha \leq 0,05 \mathrm{e}^{*}=0,08\right)$ quanto ao efeito local e sistêmico, respectivamente.

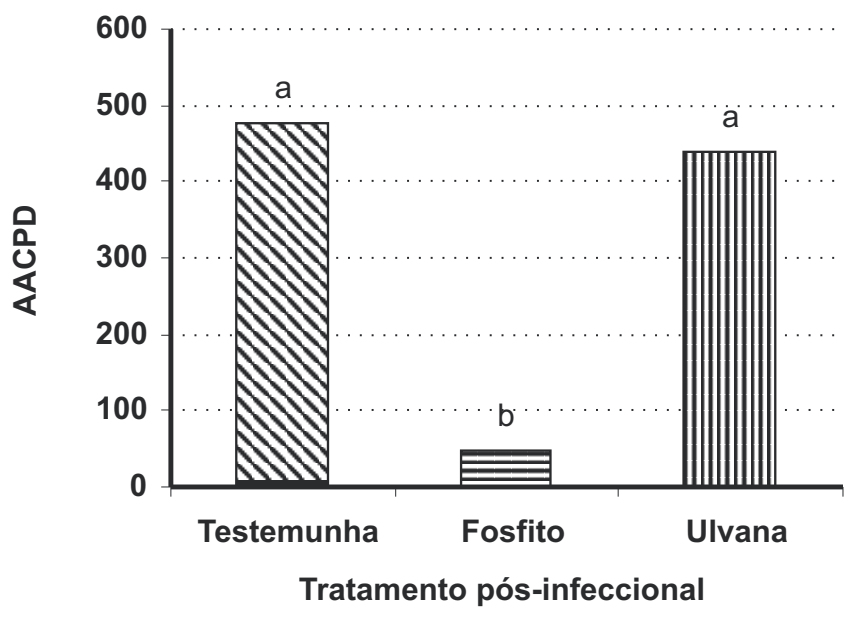

FIG. 3 - Efeito do fosfito de potássio e da ulvana sobre a área abaixo da curva do progresso da doença (AACPD) em plântulas de macieira cv. Gala tratadas $24 \mathrm{~h}$ após a inoculação com Colletotrichum gloeosporioides. Colunas com mesma letra não diferem entre si pelo teste de Tukey $(\alpha \leq 0,05)$.

acúmulo de peroxidases e $\beta$-1,3-glucanase, que se expressa tanto local como sistemicamente (Brisset et al., 2000). Os resultados deste estudo indicam que o fosfito de potássio tem ação direta sobre o fungo, enquanto a ulvana provavelmente 
induz resistência à MFG em plantas de macieira.

\section{AGRADECIMENTOS}

Os autores agradecem à Fundação de Apoio à Pesquisa Científica e Tecnológica do Estado de Santa Catarina - FAPESC pela concessão da bolsa de estudos ao primeiro autor, à Associação Brasileira dos Produtores de Maçã - ABPM e ao Programa Iberoamericano de Ciência e Tecnologia para Desenvolvimento - CYTED pelo suporte financeiro.

\section{REFERÊNCIAS BIBLIOGRÁFICAS}

Abreu GF (2005) Bioprospecção de macroalgas marinhas e plantas aquáticas para o controle da antracnose (Colletotrichum lindemuthianum) do feijoeiro (Phaseolus vulgaris L.). Dissertação de Mestrado. Universidade Federal de Santa Catarina. Florianópolis SC.

Boneti JIS, Katsurayama Y (2005) Viabilidade do uso de fosfitos no controle da sarna-da-macieira. Agropecuária Catarinense 18:51-54.

Brisset MN, Cesbron S, Thomson SV, Paulin JP (2000) AcibenzolarS-methyl induces the accumulation of defense-related enzymes in apple and protects from fire blight. European Journal of Plant Pathology 106:529-536.

Cluzet S, Torregrosa C, Jacquet C, Lafite C, Fournier J, Mercier L, Salamagne S, Briand X, Esquerré-Tugayé MT, Dumas B (2004) Gene expression profiling and protection of Medicago truncatula against a fungal infection in response to an elicitor from green algae Ulva spp. Plant, Cell and Environment 27:917-928.

Crusius LU, Forcelini CA, Sanhueza RMV, Fernandes JMC (2002)
Epidemiology of apple leaf spot. Fitopatologia Brasileira 27:6570.

Epagri (2002) A cultura da macieira. Epagri. Florianópolis SC.

Guest DI, Grant BR (1991) The complex action of phosphonates antifungal agents. Biological Review 66:59-187.

Hamada NA (2005) Caracterização morfológica, patogênica e molecular de isolados de Colletotrichum spp. em macieira. Dissertação de Mestrado. Universidade Federal de Santa Catarina. Florianópolis SC.

Klarzynski O, Plesse B, Joubert JM, Yvin JC, Koop M, Kloareg B, Fritig B (2000) Linear $\beta-1,3$ glucans are elcitors of defense responses in tobacco. Plant Physiology 124:1027-1037.

Ortega F, Steiner U, Dehne HW (1998) Induced resistance: a tool fungicide management. Pesticide Science 53:193-196.

Paulert R (2005) Atividade antimicrobiana e controle da antracnose do feijoeiro comum (Phaseolus vulgaris L.) utilizando polissacarídeo e extratos da macroalga marinha Ulva fasciata. Dissertação de Mestrado. Universidade Federal de Santa Catarina. Florianópolis SC.

Saindrenant P, Barchietto T, Avelinop J, Bompeix G (1988) Effect of phosfhite on phytoalexin accumulation in leaves of cowpea infected with Phytophthora cryptogea. Physiological and Molecular Plant Pathology 32:425-435.

Stadnik MJ, Maraschin M (2004) Manejo ecológico de doenças de plantas. In: Stadnik MJ, Talamini V (Eds.) Indução de resistência de plantas a fitopatógenos. Florianópolis SC. Centro de Ciências Agrárias, Universidade Federal de Santa Catarina. pp. 221-244.

Stadnik MJ, Paulert R (2008) Uso de macroalgas marinhas na agricultura. Série Livros do Museu Nacional. Rio de Janeiro. Volume 30. no prelo.

Steiner U, Schönbeck F (1995) Induced disease resistence in monocots. In: Hammerscmidt R, Kuc J (Eds.) Induced resistance to disease in plants. Dordrecht. Kluwer Academic Publishers. pp. 86-110.

Recebido 18 Junho 2007 - Aceito 14 Março 2008 - TPP 7070 Editor Associado: Mario Lúcio V. Resende 